\title{
Correction to: The History of Coordinated Specialty Care for Early Intervention in Psychosis in the United States: A Review of Effectiveness, Implementation, and Fidelity
}

\author{
Halley Read ${ }^{1,3}$ [D Brandon A. Kohrt ${ }^{2}$
}

Published online: 23 February 2022

C Springer Science+Business Media, LLC, part of Springer Nature 2022

\section{Correction to: Community Mental Health Journal https://doi.org/10.1007/s10597-021-00891-w}

The original version of this article unfortunately contained an error in describing one of the programs discussed in the article.

This paper inaccurately conflated the two Recovery After an Initial Schizophrenia Episode (RAISE) studies: Early Treatment Program (ETP) and Implementation and Evaluation Study (IES). The paper states that IES studied the clinical intervention NAVIGATE, which was the ETP clinical intervention. In fact, IES implemented the RAISEConnection model in New York and Maryland. Although both are examples of Coordinated Specialty Care (CSC), they are distinct programs.

In another section of the paper, the authors stated that OnTrackNY evolved from NAVIGATE whereas it evolved from RAISE-Connection. OnTrackUSA, a development of RAISE-Connection and OnTrackNY has now provided training to in 29 states/territories.

Publisher's Note Springer Nature remains neutral with regard to jurisdictional claims in published maps and institutional affiliations.
The original article can be found online at https://doi.org/10.1007/ s10597-021-00891-w.

\section{Halley Read}

readh@pacificu.edu

1 School of Occupational Therapy, College of Health Professions, Pacific University, Forest Grove, OR, USA

2 Department of Psychiatry \& Behavioral Sciences, School of Medicine and Health Sciences, The George Washington University, Washington, DC, USA

3 Department of Clinical Research \& Leadership, School of Medicine and Health Sciences, The George Washington University, Washington, DC, USA 